\title{
Unusual motor and non-motor symptoms and signs in the early stage of Parkinson's disease
}

\section{Sintomas e sinais motores e não motores pouco comuns na fase inicial da doença de Parkinson}

\author{
Hélio A. G. Teive', Délcio C. Bertucci Filho², Renato P. Munhoz ${ }^{3}$
}

\begin{abstract}
Objective: Patients with Parkinson's disease (PD) may present with unusual motor and non-motor symptoms and signs in the early stage of the disease. Methods: Cases were collected over a five-year period at two tertiary movement disorders clinics. All had a diagnosis of PD with unusual presentations defined retrospectively as the presence of complaints not objectively related to any of the classic cardinal signs of parkinsonism or the typical early non-motor features of PD. Results: A total of 15 early PD patients fulfilled the proposed criteria, presenting with symptoms such as atypical tremors, shoulder pain, signs related to the rigid akinetic syndrome, as well as cases of asthenia, rhinorrhea, parosmia, dysgeusia, nocturnal sialorrhea, and color discrimination disorders. Conclusions: Unusual motor and non-motor symptoms and signs in the early stage of PD can be difficult to interpret. Specialists should be aware of these conditions as clues to a potential diagnosis.
\end{abstract}

Keywords: Parkinson disease; signs and symptoms.

\section{RESUMO}

Objetivo: Pacientes com doença de Parkinson (DP) podem apresentar sintomas e sinais motores e não motores pouco comuns na fase inicial da doença. Métodos: Os casos foram coletados em um período de cinco anos, em dois centros terciários de distúrbios do Movimento. Todos os pacientes tinham o diagnóstico de DP com apresentações clínicas iniciais pouco comuns. Resultados: Um total de 15 pacientes com DP na fase inicial, apresentando sintomas e sinais tais como, tremores atípicos, dor no ombro, sinais relacionados com a síndrome rígido-acinética, bem como casos com astenia, rinorréia, parosmia, disgeusia, sialorréia noturna e distúrbios da discriminação de cores. Conclusões: Sintomas e sinais motores e não motores pouco comuns na fase inicial da DP podem ser de difícil interpretação. Neurologistas devem estar a par destas condições, como pistas para o potencial diagnóstico.

Palavras-chave: doença de Parkinson; sinais e sintomas.

Parkinson's disease (PD) is a progressive neurodegenerative disease typically diagnosed using a combination of motor symptoms that include bradykinesia, rigidity, tremor and postural instability. This syndrome may present within a spectrum including forms with predominant tremor, a more balanced presentation with all the first three cardinal signs described above, and a rigid-akinetic (RA) phenotype ${ }^{1,2}$. In addition, PD is associated with non-motor symptoms, including autonomic dysfunction, sleep disorders, neuropsychiatric disorders, and sensory impairment. Some non-motor symptoms can be detected very early in the disease process and even during the so-called "premotor" phase, as in the case of REM sleep behavior disorder, hyposmia, depression, and constipation ${ }^{1,3,4,5}$. Other subjective descriptions of symptoms that can occur in the early stages of PD may be ambiguous and less orthodox, including asthenia, sensation of internal tremor, shoulder pain, taste disturbance, color discrimination deficit, rhinorrhea, and parosmia.

The objective of our study is to describe a case series of Brazilian patients with clinically confirmed PD who presented with unusual and seemingly vague symptoms and signs in the early stage of the disease.

\section{METHODS}

Fifteen consecutive patients with clinically confirmed PD were evaluated over a five year period (2011-2015) at two tertiary movement disorders clinics (Hospital de Clínicas, Federal

${ }^{1}$ Universidade Federal do Paraná, Hospital de Clínicas, Serviço de Neurologia, Unidade de Distúrbios do Movimento, Curitiba PR, Brasil;

${ }^{2}$ Universidade Estadual de Ponta Grossa, Departamento de Medicina Interna, Serviço de Neurologia, Ponta Grossa PR, Brasil;

${ }^{3}$ Toronto University, Toronto Western Hospital, Movement Disorders Centre, Toronto ON, Canada.

Correspondence: Hélio A.G. Teive; Rua General Carneiro, 1103/102; 80150-600 Curitiba PR, Brasil. E-mail: hagteive@mps.com.br

Conflict of interest: There is no conflict of interest to declare.

Received 23 March 2016; Received in final form 12 June 2016; Accepted 30 June 2016. 
University of Paraná and Paraná Parkinson's Association), and the private offices of the authors (HAGT and RPM). All selected patients provided a retrospective description of unusual symptoms or signs that could be linked to a recognized motor or non-motor sign, or to a previously-known unusual presentation of PD from the literature. The identification of these findings was based on the expertize and clinical suspicion of the authors as no guidelines have been established for this purpose. From the patients' perspective, the findings were described as trivial and perplexing but recurrent, often related to sensations, including awkwardness that could be self-generated (internal tremor, parosmia, etc.) or generated by external elements (watch or clothing).

The patients were staged using the Hoehn \& Yahr scale (H\&Y) and also classified into two combinations of cardinal motor signs according to the presence of rest tremor [RA or tremor with rigidity and/or bradykinesia]. Informed consent forms were obtained from patients, and the study was approved by the local ethics committee.

\section{RESULTS}

An overview of all 15 individual patients identified with a description of the unusual symptoms and signs is shown in Table. Mean age was $64 \pm 4.6(58-72)$ years, 12 (80\%) were male. Mean H\&Y scale score at the time of diagnosis was $1.5 \pm 0.4$ (median 1.5, range 1-2) and mean time from detection of symptom or sign until the formal diagnosis of PD was $12.9 \pm 6.2$ (5-24) months. The RA form of parkinsonism was observed in 12 (80\%) of cases and the most affected side was the dominant in eight (53.3\%) patients. Among all eight patients in whom the observed symptom or sign could be lateralized, the side not surprisingly coincided with the most affected body side. Some degree of levodopa responsiveness of the observed symptom or sign was observed in 12 (80\%) cases.

\section{DISCUSSION}

In this series, we describe 15 patients with $\mathrm{PD}$, all diagnosed during the early initial stages, who retrospectively described unusual symptoms and signs eventually attributable to the disease but regarded as non-specific and vague for several months. In all cases, the description or finding was not part of the diagnostic criteria and, for obvious reasons, could not contribute per se to the diagnosis of PD. Our experience, however, leads us to believe that part of what we describe here can be used as unambiguous clues for the active search of the classic cardinal signs of parkinsonism. One of the interesting findings of our series is the fact that the vast majority of cases present with the RA motor combination of cardinal signs with no rest tremor. This motor phenotype represents about one in every four cases of established PD in clinical practice and our finding may indicate that, different from the visual and more straightforward objective detection of tremor, the interpretation of the sensation and physical signs related to rigidity and bradykinesia can be complex and treacherous. Also, although tremor, even among our cases with "unusual" presentations, was detected as an involuntary self-produced abnormality, symptoms related to rigidity and bradykinesia were often attributed to external sources, such as a defective watch or an unskilled tailor. Other descriptions, such as dysgeusia for specific kinds of food, parosmia, fatigue, and color discrimination deficits are, in fact, misperceptions of known early non-motor aspects of PD. Finally, a minority of the descriptions in our series have been reported previously, including rhinorrhea and sialorrhea, but are not entirely attributable to any single motor or non-motor sign or symptom of PD. The improvement and amount of responsiveness to levodopa may be clues to the potential source of the given unusual symptom.

In fact, PD patients may present with a variety of motor and non-motor signs and symptoms that are considered uncommon or rare ${ }^{1,3,4,5}$. The motor signs in this series included tremor with an unusual presentation reported by three patients. The complaints included sensation of internal tremor, unilateral foot tremor during sexual intercourse, and tongue tremor producing what is regarded as a "disapproval" click sound in many cultures. Internal tremor was described by Shulman et al. ${ }^{6}$ and defined as a sensation of tremor in the extremities or trunk that produces no visible movement. More recently, Cochrane et al. studied the presence of internal tremor in PD, multiple sclerosis and essential tremor, concluding that it represents a common but under-recognized symptom in all three diseases, and was found in $32.5 \%$ of PD patients ${ }^{7}$. Unilateral lower extremity and tongue tremors are not rare $^{8}$, but the specific circumstances and impact in the particular patients outlined here were filled with descriptions of embarrassment and perplexity. One previous description of throat clicking, possibly related to tremor has been described, raising the possibility of palatal tremor.

Other atypical motor manifestations related to a unilateral RA syndrome included signs related to shirt buttoning, jacket sleeve length, new onset problems with shoe sole and laces, and the Rolex sign, which was reported by Andrade and Ferraz in 1996. This sign is related to malfunctioning of a self-winding wristwatch due to upper extremity bradykinesia". The term "Rolex sign" was suggested by the late professor David Marsden during a neurology meeting in Brazil ${ }^{9,10}$. We interpret the signs related to shirt buttoning and tying shoe laces as subtle motor manifestations of bradykinesia and declining hand dexterity found in the initial stages of $\mathrm{PD}^{11}$. Similarly, the sensation of short jacket length can be seen as a sign related to a combination of bradykinesia, rigidity, and abnormal posturing of the $\operatorname{arm}^{11}$. The worn shoe sole sign is potentially related to 
Table. Demographic and clinical description of cases with unusual initial manifestation of Parkinson's disease.

\begin{tabular}{|c|c|c|c|c|c|c|c|c|}
\hline & Age & Gender & $\begin{array}{l}\text { Months before } \\
\text { diagnosis }\end{array}$ & Initial symptom or sign & H\&Y stage & $\begin{array}{l}\text { Motor } \\
\text { phenotype }\end{array}$ & $\begin{array}{l}\text { Motor } \\
\text { laterality }\end{array}$ & $\begin{array}{l}\text { Change } \\
\text { with L-dopa }\end{array}$ \\
\hline 1 & 65 & M & 12 & Night time rhinorrhea & 1 & RA & D & +++ \\
\hline 2 & 70 & M & 7 & Dysgeusia for wine and refined food & 1 & RA & ND & N \\
\hline 3 & 63 & M & 24 & Color discrimination deficit & 1.5 & RA & D & N \\
\hline 4 & 59 & M & 15 & Parosmia, followed by hyposmia & 2 & RA & ND & + \\
\hline 5 & 66 & M & 5 & $\begin{array}{l}\text { Malfunctioning of a self-winding } \\
\text { wristwatch }{ }^{1}\end{array}$ & 2 & RA & ND & $++^{2}$ \\
\hline 6 & 72 & $\mathrm{~F}$ & 24 & Generalized internal tremor sensation & 2 & TRB & D & +++ \\
\hline 7 & 58 & M & 6 & Shoulder pain & 1 & RA & D & +++ \\
\hline 8 & 71 & M & 12 & Unilateral shirt sleeve buttoning difficulty ${ }^{3}$ & 2 & RA & D & ++ \\
\hline 9 & 64 & $\mathrm{~F}$ & 20 & Excessive night time sialorhea ${ }^{4}$ & 2 & RA & D & $\mathrm{N}$ \\
\hline 10 & 59 & M & 18 & $\begin{array}{c}\text { Sensation of unilateral short length of } \\
\text { jacket sleeve }\end{array}$ & 1.5 & RA & ND & ++ \\
\hline 11 & 63 & M & 8 & Unilateral worn shoe sole & 1.5 & RA & D & + \\
\hline 12 & 60 & M & 9 & Fatigue and asthenia & 1.5 & RA & ND & +++ \\
\hline 13 & 68 & M & 12 & Coital foot tremor & 1 & TRB & ND & ++ \\
\hline 14 & 60 & $\mathrm{~F}$ & 8 & Unilateral difficulty doing shoe laces & 1 & RA & D & + \\
\hline 15 & 62 & M & 14 & $\begin{array}{c}\text { Continuous "disapproval” tongue-palate } \\
\text { click (tremor) }\end{array}$ & 1.5 & TRB & ND & ++ \\
\hline
\end{tabular}

H\&Y: Hoehn Yahr;M:male;F:female;RA: rigid akinetic;TRB: parkinsonism presenting tremor, rigidity and bradykinesia; D: dominant body side; ND: non-dominant; N: none; "Rolex sign",10; ${ }^{2}$ Improved after watch was switched to contralateral wrist, while on L-dopa; 3,4,5refered by the patients as "the shirt's button sign", "wet pillow sign", and "short jacket's sleeve sign".

a shuffling gait with unilateral leg dragging ${ }^{12}$. Pain is considered a common sign in PD patients and can be of different types. Goetz studied pain in PD patients and classified musculoskeletal, dystonic and joint pain as the most common types ${ }^{13}$. Back pain can be an early sign of PD, related to rigidity and bradykinesia and can be confused with a painful shoulder syndrome of orthopedic origin ${ }^{14,15,16,17}$. In fact, ultrasound imaging in the shoulder region in $33 \mathrm{PD}$ patients found abnormalities in $22(66.6 \%)$, including tendon tearing, the supraspinatus muscle being the most common site involved ${ }^{18}$.

Fatigue and asthenia can be observed in the initial stages of PD and may be related to the combination of RA syndrome and apathy, fatigue and depression ${ }^{19}$. Rhinorrhea unrelated to allergy, sinus disease or respiratory tract infections can occur in PD patients ${ }^{20}$. Kano et al. ${ }^{20}$ conducted a multicenter study of 231 PD patients in Japan and compared them with a control group, finding greater frequency of rhinorrhea in PD patients (33.3\%) but failing to find a correlation with disease duration, H\&Y score and the clinical presentation. Dysgeusia is an uncommon spontaneous complaint in PD patients; however Kashihara et al..$^{21}$ actively looked for this symptom and hyposmia in 285 PD patients. Almost $43 \%$ complained of both smell and taste impairment, $39.3 \%$ of smell impairment and almost $10 \%$ of isolated taste impairment. Both were more common at more advanced stages of $\mathrm{PD}^{21}$. Olfactory dysfunction is common in PD patients as a quite early non-motor symptom ${ }^{22,23}$. Doty estimated that $90 \%$ of PD patients present with a complaint of olfactory dysfunction in the initial stages of the disease. ${ }^{22}$
Parosmia, which is defined as distorted odor perception in the presence of an odor source, is a much less frequent non-motor sign in PD patients ${ }^{23}$.

Drooling is defined as excessive pooling and spillover of saliva out of the oral cavity and is considered one of the most unpleasant non-motor symptoms by patients and caregivers ${ }^{24}$. The main factor that causes drooling in PD patients is impaired intra-oral salivary clearance $e^{24}$. Drooling is more common in PD patients in the advanced stages of the disease and is uncommon in the initial stages ${ }^{24}$. Nocturnal drooling, which is known as the pillow sign, is less common in the early stages of PD. Finally, impaired color discrimination has been suggested as an early, yet less common, sign in PD patients, related to dopaminergic dysfunction ${ }^{25}$. Kertelge et al. ${ }^{25}$ studied impaired olfaction and color discrimination in $100 \mathrm{PD}$ patients, finding a high prevalence of impaired olfaction (hyposmia) and diminished color discrimination in the Farnsworth-Munsell test. Reduced color discrimination was more common in patients with the LRRK2 and parkin mutations.

In conclusion, PD is a complex neurodegenerative disease that manifests with classic motor signs and countless non-motor symptoms and signs. In the initial stages of PD, uncommon motor and non-motor signs can be observed. Difficulty with precise description and interpretation, as well as atypical forms of tremor, pain, other modalities of sensation, and secondary signs of RA syndrome make the initial diagnosis even more challenging but may also be clues for the active pursuit of non-obvious cardinal signs of the disease. 
1. Munhoz RP, Werneck LC, Teive HA. The differential diagnoses of parkinsonism: findings from a cohort of 1528 patients and a 10 years comparison in tertiary movement disorders clinics. Clin Neurol Neurosurg. 2010;112(5):431-5. doi:10.1016/j.clineuro.2010.03.003

2. Thenganatt MA, Jankovic J. Parkinson disease subtypes. JAMA Neurol 2014;71(4):499-504. doi:10.1001/jamaneurol.2013.6233

3. Silveira-Moriyama L, Lees AJ. Parkinson disease: how reliable are prodromal indicators of Parkinson disease? Nat Rev Neurol. 2015;11(1):5-6. doi:10.1038/nrneurol.2014.235

4. Munhoz RP, Teive HA, Eleftherohorinou H, Coin LJ, Lees AJ, Silveira-Moriyama L. Demographic and motor features associated with the occurrence of neuropsychiatric and sleep complications of Parkinson's disease. J Neurol Neurosurg Psychiatry. 2013;84(8):883-7. doi:10.1136/jnnp-2012-304440

5. Munhoz RP, Moro A, Silveira-Moriyama L, Teive HA. Non-motor signs in Parkinson's disease: a review. Arq Neuropsiquiatr. 2015;73(5):454-62. doi:10.1590/0004-282X20150029

6. Shulman LM, Singer C, Bean JA, Weiner WJ. Internal tremor in patients with Parkinson's disease. Mov Disord. 1996;11(1):3-7. doi:10.1002/mds.870110103

7. Cochrane GD, Rizvi S, Abrantes A, Crabtree B, Cahill J, Friedman $\mathrm{JH}$. Internal tremor in Parkinson's disease, multiple sclerosis, and essential tremor. Parkinsonism Relat Disord. 2015;21(10):1145-7. doi:10.1016/j.parkreldis.2015.07.014

8. Hellmann MA, Melamed E, Steinmetz AP, Djaldetti R. Unilateral lower limb rest tremor is not necessarily a presenting symptom of Parkinson's disease. Mov Disord. 2010;25(7):924-7. doi:10.1002/mds.23030

9. Teive HA, Sá DS. The Rolex sign: first manifestation of Parkinson's disease: case report. Arq Neuropsiquiatr. 2000;58(3A):724-5. doi:10.1590/S0004-282X2000000400020

10. Manfredi M, Teive HA, Pedace T, Andrade LAF, Ferraz HB, Curra A. C. David Marsden and Rolex sign. Neurol Sci. 2003;24(1):45-6. doi:10.1007/s100720300023

11. Kwon KY, Kim M, Lee SM, Kang SH, Lee HM, Koh SB. Is reduced arm and leg swing in Parkinson's disease associated with rigidity or bradykinesia? J Neurol Sci. 2014;341(1-2):32-5. doi:10.1016/j.jns.2014.03.041

12. Ebersbach G, Moreau C, Gandor F, Defebvre L, Devos D. Clinical syndromes: parkinsonian gait. Mov Disord. 2013;28(11):1552-9. doi:10.1002/mds.25675

13. Goetz CG, Tanner CM, Levy M, Wilson RS, Garron DC. Pain in Parkinson's disease. Mov Disord. 1986;1(1):45-9. doi:10.1002/mds.870010106
14. Cleeves L, Findley L. Frozen shoulder and other shoulder disturbancies in Parkinson's disease. J Neurol Neurosurg Psychiatry. 1989;52(6):813-4. doi:10.1136/jnnp.52.6.813-b

15. Stamey W, Davidson A, Jankovic J. Shoulder pain: a presenting symptom of Parkinson disease. J Clin Rheumatol. 2008;14(4):253-4. doi:10.1097/RHU.0b013e3181826d43

16. Kim YE, Lee WW, Yun JY, Yang HJ, Kim HJ, Jeon BS.

Musculoskeletal problems in Parkinson's disease: neglected issues. Parkinsonism Relat Disord. 2013;19(7):666-9. doi:10.1016/j.parkreldis.2013.03.002

17. Berardelli A, Conte A, Fabbrini G, Bologna M, Latorre A, Rocchi L et al. Pathophysiology of pain and fatigue in Parkinson's disease. Parkinsonism Relat Disord. 2012;18(Suppl 1):S226-8. doi:10.1016/S1353-8020(11)70069-4

18. Koh SB, Roh JH, Kim JH, Oh K, Kim BJ, Kim GS et al. Ultrasonographic findings of shoulder disorders in patients with Parkinson's disease. Mov Disord. 2008;23(12):1772-6. doi:10.1002/mds.22191

19. Cochrane GD, Rizvi S, Abrantes AM, Crabtree B, Cahill J, Friedman $\mathrm{JH}$. The association between fatigue and apathy in patients with either Parkinson's disease or multiple sclerosis. Parkinsonism Relat Disord. 2015;21(9):1093-5. doi:10.1016/j.parkreldis.2015.07.007

20. Kano O, Yoshioka M, Nagayama H, Hamada S, Maeda T, Hasegawa Tet al. Rhinorrhea in Parkinson's disease: a consecutive multicenter study in Japan. J Neurol Sci. 2014;343(1-2):88-90. doi:10.1016/j.jns.2014.05.039

21. Kashihara K, Hanaoka A, Imamura T. Frequency and characteristics of taste impairment in patients with Parkinson's disease: results of a clinical interview. Intern Med. 2011;50(20):2311-5. doi:10.2169/internalmedicine.50.5935

22. Doty RL. Olfactory dysfunction in Parkinson's disease. Nat Rev Neurol. 2012;8(6):329-39. doi:10.1038/nrneurol.2012.80

23. Silveira-Moriyama L, Munhoz RP, Carvalho MJ, Raskin S, Rogaeva E, Aguiar PC et al. Olfactory heterogeneity in LRRK2 related Parkinsonism. Mov Disord. 2010;25(16):2879-83. doi:10.1002/mds.23325

24. Srivanitchapoom P, Pandey S, Hallett M. Drooling in Parkinson's disease: a review. Parkinsonism Relat Disord. 2014;20(11):1109-18. doi:10.1016/j.parkreldis.2014.08.013

25. Kertelge L, Brüggemann N, Schmidt A, Tadic V, Wisse C, Dankert S et al. Impaired sense of smell and color discrimination in monogenic and idiopathic Parkinson's disease. Mov Disord. 2010;25(15):2665-9. doi:10.1002/mds.23272 